\title{
Experimental Study to Develop Writing skills through Blended Learning in the Times of Internet+
}

\author{
Cui Guangying ${ }^{1} \quad \mathrm{Hu}^{\mathrm{Jiahao}^{2}}$ \\ ( ${ }^{1}$ School of foreign languages, Huazhong University of Science and Technology, Wuhan, Hubei 4300702 School of international \\ education, Wuhan Sports University, Wuhan, Hubei 430079 The corresponding author is Jiahao Hu)
}

\begin{abstract}
Blended learning emphasizes the role of computer-based technologies in learning how to develop writing skills. Through BL, learners not only control the learning speed, but also do not suffer from the time restrictions of classroom interaction. Teaching and learning take place in both on-campus and online setting and various ways are offered to communicate with each other, either synchronously or asynchronously. Compared to paper teaching documents, the electronic resources are easier for the teachers to keep in order. On the other hand, blended learning leaves a significant role for students' classroom learning. The effect of BL in developing writing skills has been done through a half-year empirical study. Over the period of half a year, the students' writing skills have been tracked through interviews, learning contracts and teacher observations. The empirical application illustrates the features and advantages of $\mathrm{BL}$ approach.
\end{abstract}

\section{Introduction}

In the times of information and communication technologies, internet has accompanied us every moment in any place. It is also a useful tool to develop our writing skill on the road to learn English. The rapid development of internet technology facilitates composition writing process by offering a wide variety of authentic materials. Blended-learning (abbreviated as BL) approach, a combination of the traditional face-to-face learning and certain aspects of internet learning, has been widely adopted in college writing course. At present empirical study on its effects has seldom been found. So it is of great necessity to investigate the results of $\mathrm{BL}$ approach to develop writing skills.

\section{What is $B L$ ?}

Blended Learning originating from the career training in business company has aroused academic attention as it provides students with more opportunities to apply what they learn in class into the reality. It is hard to find a precise and unitary definition of blended learning. In the book entitled Blended Learning Systems: Definition, Current Trends, and Future Directions, Graham made contribution to define BL, stating that blended learning is the combination of instruction from two historically separate models of traditional learning systems and distributed learning systems. He emphasizes the central role of computer-based technologies in blended learning. The two separate modes of teaching and learning are so different that combinations of different media are adapted respectively to meet the needs of different learners.
Face-to-face learning is dominated by teachers, focusing on person-to-person contact. However, the internet learning happens in an opposite direction. The interaction with learning materials tends to be asynchronous and self-paced. Rapid development of technological innovations facilitates great possibilities for communication in the field of English learning and teaching. As computer-mediated instructional elements integrate into the traditional learning more and more, the BL tendency urges us to prepare for this significant development in the times of Internet + .

\section{Features of BL and advantages of BL}

Communication and collaborative learning can be facilitated through internet-based tools, therefore, BL promotes the following features of language teaching and learning:

\subsection{Features of BL}

\subsubsection{Self-paced and collaborative learning}

Through BL, learners not only control the speed of information they are acquiring, but also do not suffer from the restrictions of interaction in the classroom. The internet provides BL learners with access to information any time. Generally the learner's responsibilities are consistent with the instruction of a traditional classroom, reading, writing and familiarizing the material with which the instructor supplies him. As long as the cooperative learning is concerned, blended learning contains the process where learning takes place through 
cooperative efforts, creating a live learning environment dependent on dynamic communication between learners that fosters knowledge sharing (Singh, 2003). The power of self-paced learning experience is increased where opportunities for meaningful collaboration are present.

\subsubsection{On-campus and online learning}

In BL, teaching and learning take place both on campus and on line. On campus the instruction happens in a traditional environment while online education usually occurs on the internet. The dual settings of study are perfectly combined to stimulate interaction, establish communication, and share content. The length of time students spent on the activity online or in the classroom is usually decided on the nature of the course and the choice of the instructor.

\subsubsection{Synchronous and asynchronous communication methods}

Various ways to communicate, either synchronous or asynchronous, are offered to the participants of BL. Synchronous tools such as web conferencing, video conferencing and telephone, etc. are widely used. Asynchronous tools such as e-mail, fax, online environment and post are also very popular tools used in daily life. Online discussions have the possibility to improve students' learning and may lead to cognitive development if the participants neglect their race, gender, educational background or social status. The traditional classroom learning allows for fast and efficient exchanges of ideas. Synchronous discussions are extremely beneficial for those who miss the chances to participate in. On the other hand, asynchronous communication leaves enough time for students to reflect and react to others. Online discussions enable them to work at their own pace with flexible working hours. Whenever or wherever they encounter problems, they submit questions to instructors, receive their responses and solve the problems. Otherwise, they need to wait until the next meeting with the instructors.

\subsection{Advantages of BL}

\subsubsection{More flexibility and effectiveness for teachers}

Compared to paper teaching documents, the electronic resources are easier for the teachers to keep in order. Teacher's online feedback to a student's task saves a lot of time for tedious grading work. In addition, the course build-in tools are extensive and allow teachers to include dynamic, news-based and skill-based elements. Event in the morning news, any up-to-the-minute data can all be included in the writing course. Teachers can save a lot of time to find authentic teaching material. With more free time teachers may arrange interaction with students in need of much more helpful guidance. Students' interactive exercises can be recorded, which also makes it easier for teachers to keep track of students work. Once teachers get access to the learning logs of the class, they know whether each student is active to participate in the learning and check out what he is doing, for how long he studied. Furthermore teacher can analyze the data to check their mastery of the materials, highlight the difficult points of each lesson and judge students' progress more accurately. Later in the following classroom teaching, teacher adds more elaborate clarification to solve student's problems. Making full use of the learning $\log$ and its statistical functions, teacher can get first-hand data to do research work to improve their teaching.

\subsubsection{More flexibility and effectiveness for students}

In online environment, advanced students can choose to do some other new things. They are free to choose learning content and focus on the difficult part to reach the higher standard of the course. Those who are slow to grasp the content can learn it in advance and try to meet the lower standard. They can also choose to spend more time learning it for deep and better understanding. In addition, students needn't worry about missing the classes during their absence for some other urgent reasons. They can find any suitable time to learn and make it up. On the other hand, blended learning leaves a significant role for students' classroom learning. Not every student is good at online technology. They struggle against the multi-media environment. Due to internet difficulties, sometimes system problems cannot be avoided. Classroom interaction provides an opportunity to display knowledge and acquisition of required skills.

\section{Application of BL Approach to develop writing skills}

In blended writing class, students are required to have the computer-based autonomous learning with the help of computers. The students should meet their teachers in classroom, where real-life situations are created for them to produce meaningful output with each other. Teachers will provide guidance and feedback to check students' online writing quality. In addition, students are encouraged to participate in various extracurricular writing activities. Peer writing groups are formed within a class, which enhances the value of student-student interaction and results in various advantageous learning outcomes.

\subsection{Computer-based autonomous learning}

In computer-based autonomous writing, students must complete the autonomous writing tasks in the computer-based environment. They need to put what they have learned from the computer into practice, communicate and corporate with their classmates to complete some writing tasks that teachers assign in traditional classrooms. In these two phases, teachers should monitor and facilitate students' online writing and organize the classroom activities. Students should finish some extra writing assignments after class with their 
partners; proficient students must make proper arrangements and make sure that everything functions well.

Computer-based autonomous learning courseware is essential equipment in the whole writing process. The internet-based software used in the research contains three phases: Presentation, Practice and Extension. In the presentation stage new language is presented to students in a context which enables them to understand. In the practice stage, students repeat to write what they have learned, initially mechanically and then more creatively, with feedback from the computers on accuracy and fluency. In the extension stage, writing skills are used in an authentic communicative context. Students can learn writing skills through many interesting video stories or interviews. In such an enjoyable learning atmosphere, students' enthusiasm can be highly stimulated.

\subsection{Face-to-face classroom instruction}

No matter how many advantages a computer can bring about, it cannot diminish the importance of the teacher's role. After sufficient online writing exercises, students need to meet their teachers once a week to write what they have learned in web-classrooms to make genuine communication in real-life situations.

In Blended Learning context, online and offline teacher-student interactions are important factors for writing. Therefore, writing skills can be described as an interactive, dynamic process, in which new knowledge is most fruitfully acquired when learners are placed in a situation where they can explore sources rather than in a context of mere formal instruction. Teachers serve as facilitators and guides rather than directors and molders of students' learning. So in classroom, the teacher's role is to get students to take responsibility for their own writing, to be critical thinkers, to develop integrated understanding of concepts, and to pose and seek to answer important questions.

\subsection{Peer learning in extracurricular writing activities}

King (1999) maintains that peer learning is an educational practice in which students interact with other students to attain educational goals. It is a form of cooperative learning that enhances the value of student-students interaction and results in various advantageous learning outcomes. As students communicate with each other, they inevitably assume leadership roles, acquire conflict-managing skills, discuss and clarify concepts, and unravel the complexities of human relationships within a given context.

Writing Club is such an extracurricular studying organization which can provide a platform for students to discuss issues, exchange their viewpoints and engage in cooperative learning. The club often arranges case studies and integrated projects. Those are effective teaching strategies that stir students' enthusiasm and encourage peer learning. Students thus have diverse opportunities to experience in a reasonably safe and unconstrained context, reactions to complex and real problems they may face later in their careers.

\subsection{Effects of the application}

In order to test the effect of BL in developing writing skills, a half -year empirical study has been carried out. Over the period of half a year, the students' writing skills have been tracked through interviews, learning contracts and teacher observations

\subsubsection{Interview results}

The interview was conducted to provide insight into the students' attitudes to the BL approach. The interview consists of two parts: structured questions and unstructured questions. The structured questions were in the form of multiple choices. Students could choose more than one choice for each question. They serve both as students' needs analysis before the study and their self-evaluation after the BL writing training. After the interview with the students, what impressed most was that when asked about the reason for loving to study by using BL model, students were highly motivated, and more active than being asked about the other questions. Both the students who performed well and those who did not in the learning activities said that they loved to spend time practicing writing with so many original materials on the internet platform. They enjoyed a lot from various activities there. They could study with less pressure than that in the traditional teacher-centered classroom, with more freedom to manage the schedule, to choose which materials to study with, which writing skill to practice, in short, it was more convenient to do writing exercises. It enabled them to learn at their own pace, and to promote and enhance their memory. Some said they could look for the related information in time. Especially, they loved to communicate on the on-line classroom very much, where they could express opinions about writing without pressure. It proves that when given enough respect and rights, students could do better than ever before. By the result of the interviews, it's not difficult to understand why most of the students chose to use BL approach instead of the traditional teaching to practice writing in the questionnaire, and why students can make such big progress after the application.

\subsubsection{Observation results}

The author of this paper kept a continuous observation diary all through the half year of students in order to get the first hand material to assess the effectiveness of the BL approach and to obtain some further valuable pieces of information. Each student was clearly aware of his learning contents and a set learning plan before the classes started. Teachers checked their contract on the net and got information of their preparation work via e-mail to ensure that each of them makes a good preparation, thus the cooperative activities under the autonomous learning ideology would not become a mere formality. It is this communicative environment that makes students 
realize their responsibilities to learn how to write. Most students logged on with pseudonym which was their ID name in most online communities, they felt more comfortable to write what they were thinking without so much hesitation or anxiety of making mistakes, although sometimes some of them tended to go to extremes. As a matter of fact, many students self-corrected the mistakes they made by sending the follow-up messages in fragments. Others would also like to give suggestions on the mistakes in their peers' messages. Learners who were more reserved were often more likely to interact when text chat options were available.

Through the BL approach, students' autonomous writing abilities have been improved, especially in the aspects that they were quite clear about how to take their responsibility for the group work, how to choose appropriate writing strategies, how to monitor the writing process, how to evaluate their writing results, so that they can perform more positively in the group. Students took positive attitude towards cooperative activities. They believed writing with peers helped them learn more from others and reflect on their own writing methods. It also helped them in deciding about the most proper writing strategies for themselves. The majority of students held the opinion that the novel BL approach helped them to further develop their writing potentials than the teacher-centered model, develop their team spirit, and improve their writing ability.

\section{Conclusion}

In the times of internet+, BL approach promotes the combination of information technology and traditional classroom leaning. The application in the writing course illustrates the features and advantages of BL approach. BL approach promotes students' cooperation ability, which is beneficial to creating a pleasant writing atmosphere and establishing a harmonious relationship among the students. They can continuously enrich and broaden their writing knowledge via many ways, from native-speaker pen pals, or from proficient fellow students. In collaboration with others, students learn how to deal with problems, and then to give or receive help, share their ideas and listen to others' perspectives, seek new ways of solving puzzles. Thus, students' independent thinking and writing ability are greatly enhanced in peer writing. In addition, BL approach increases students' motivation and autonomy. It is found that students appear to have more interest in writing. They enjoy their writing classes and often take part in the extracurricular writing activities. This hybrid method was more effective in promoting learners' confidence, students were motivated and autonomous to write.

\section{References}

1. Graham, C. R. (2006, May). Models of blended learning in higher education. Presentation at the Workshop on Blended Learning and Higher Education: Blended Learning, Localness, and Outreach Chicago, IL.
2. Singh, H. (2003). Building Effective Blended Learning Programs. Educational Technology, 43(6), 51-54.

3. King, A. (1999). 'Discourse patterns for mediating peer learning.' In A. M. O'Donnell \& A. King (Eds.), Cognitive perspectives on peer learning (pp. 87-115). Mahwah, NJ: Erlbaum.

4. Kaye Thorne, (2003). How to Integrate Online and Traditional Learning.

5. Seljan, Sanja. (2006). Proceedings of the 29th International convention MIPRO 2006.

6. Worthington, T. (2008). Blended Learning : Using a Learning Management System Live in the Classroom in Australian National University Linking Research and Teaching Swap Shop. 